\title{
Queen pheromones in Temnothorax ants: control or honest signal?
}

Elisabeth Brunner ${ }^{1 *}$, Johannes Kroiss ${ }^{1,2}$, Andreas Trindl $^{1}$, Jürgen Heinze ${ }^{1}$

\begin{abstract}
Background: The division of reproductive labor among group members in insect societies is regulated by "queen pheromones". However, it remains controversial whether these are manipulative, i.e., actively suppress worker reproduction, or honestly signal the fertility status of the queen to which workers react in their own interest by refraining from laying eggs. Manipulative queen control is thought to lead to an evolutionary arms race between queens and workers, resulting in complex queen bouquets that diverge strongly among different populations and species. In contrast, honest signals would evolve more slowly and might therefore differ less strongly within and among species.

Results: We aimed at determining the tempo of the evolution of queen signals in two ways. First, we investigated whether queens of Temnothorax ants are capable of controlling egg laying by workers of their own, closely, and distantly related species. Second, we compared the species- and caste-specific patterns of cuticular hydrocarbons, which are assumed to convey information on reproductive status. In mixed-species colonies, queens were not able to fully suppress egg-laying and male production by workers of unrelated species, while workers did not reproduce under the influence of a queen from their own species. Furthermore, the chemical profiles differed more strongly among queens of different species than among the respective workers.

Conclusions: Our results suggest that cuticular hydrocarbons associated with fecundity are not fully conserved in evolution and evolve slightly faster than worker-specific components in the blend of cuticular hydrocarbons. While this higher rate of evolution might reflect an arms race between queens and workers, the observation that workers still respond to the presence of a queen from another species support the honest signal hypothesis. Future studies need to examine alternative explanations for a higher rate of evolution of queen-specific substances, such as an involvement of such compounds in mating.
\end{abstract}

\section{Background}

The efficiency and integrity of the societies of ants, bees, and wasps relies on a well-controlled division of reproduction $[1,2]$. Workers rarely lay eggs in the presence of a fertile queen $[3,4]$. This is surprising, as workers are more closely related to their own sons $(r=0.5)$ than to the sons of the queen $(r=0.25)$ and in queenless conditions are usually capable of producing male offspring from their own, unfertilized eggs $[5,6]$.

Complete worker sterility benefits the queen, which should be selected to inhibit worker reproduction. However, overt aggression by the queen is very rare and appears restricted to very small colonies [7-10]. Instead,

\footnotetext{
* Correspondence: Elisabeth.Brunner@biologie.uni-regensburg.de

'LS Biologie I, Universität Regensburg, 93040 Regensburg, Germany

Full list of author information is available at the end of the article
}

reproduction appears to be controlled chemically by glandular or cuticular pheromones $[11,12]$. In honeybees, secretions from the mandibular glands and other sources are thought to regulate egg laying in the hive [reviewed in $[13,14]]$. In contrast, the chemical composition of cuticular waxes is correlated with fecundity in a wide and diverse range of species of ants. This suggests the involvement of cuticular hydrocarbons in the regulation of reproduction $[11,12]$, and indeed, 3-methylhentriacontane has recently been shown to regulate worker sterility in the ant Lasius niger [15].

The question why workers respond to queen pheromones by foregoing their own reproduction is a special case of the more general, fundamental problem of whether intraspecific communication is honest or manipulative. Queen-specific chemicals might act as
C Biomed Central

C 2011 Brunner et al; licensee BioMed Central Ltd. This is an Open Access article distributed under the terms of the Creative Commons Attribution License (http://creativecommons.org/licenses/by/2.0), which permits unrestricted use, distribution, and reproduction in any medium, provided the original work is properly cited. 
primer pheromones that actively suppress the ovaries of workers $[16,17]$. However, it has been argued that such inhibitive queen control were instable in evolution if acting against the fitness interests of the workers [18]. Mutations rendering workers insensitive to queen inhibition would spread in the population, again changing the selection pressures on queens and favoring queen mutations that qualitatively or quantitatively changed their manipulative agents. The resulting arms race between queens and workers would eventually lead to more and more complex pheromone mixtures. As an alternative, pheromones produced by the queens might honestly signal their level of fertility. Workers might respond in their own interest, e.g., to avoid being attacked ("policed") by the queen or other workers [11,18-21]. Worker altruism might therefore be "enforced" [21-25].

Honest signaling requires that the quantity or quality of queen pheromones is strictly associated with their level of fertility and mating status [18]. This, however, is often not the case. For example, unmated reproductives may produce similar pheromonal bouquets as mated reproductives $[11,22]$. Furthermore, the hypothesis of manipulative regulation of reproduction appears to gain renewed support from the observation that, at least in honeybees, the regulation of reproduction is based on a very large number of substances from multiple glands [13,14].

Distinguishing between queen control and honest signaling is difficult without detailed knowledge about the molecular and cellular mechanisms involved. However, both mechanisms might leave different traces in evolution [11]. The series of manipulation and countermanipulation associated with the scenario of queen control results in a rapid evolution of queen compounds. Queen pheromones therefore likely differ even between related species. In contrast, honest signals are expected to be more stable in evolution and to evolve more slowly. Unfortunately, little is known about the variation of fertility-associated chemical compounds among related species. In this study, we compared the composition of worker and queen cuticular hydrocarbons among different species of the ant genus Temnothorax. In addition, we investigated whether workers begin laying eggs in the presence of a queen from another, closely or distantly related species. We hypothesized that with queen control and rapid evolution, queens should be less efficient in suppressing ovary development by workers from another species. Furthermore, we expected the chemical bouquet of queens to differ more between species than those of workers. In contrast, in the case of honest signaling, workers would react to fertility signals by queens from another species, and the bouquets of queens from different species would be not more different than those of workers.

\section{Results}

Worker ovary activation and male-production by workers

Experimental colonies, in which queens and workers either belonged to the same species or to different species, were created by exchanging worker pupae among colonies. Ovary dissection showed that all queens had elongated ovaries with numerous yellow bodies and maturing eggs, i.e., they were fully fertile. None of the workers in the control colonies had activated ovaries (colony groups NN, CC, UU, and RR; Figure 1a-d). Though we had observed sporadic worker egg-laying in queenright colonies of $T$. recedens in a previous study (unpublished data), dissection data did not corroborate this result for the presently studied colonies.

In all queenless colonies, the ovaries of several workers were activated (Figure 1a-d). This indicates that workers are capable of activating their ovaries within six weeks after removal of the queen. Fertile workers were also found in some of the mixed-species colonies, such as RC (Figure 1b), CU (Figure 1c), NR and CR (Figure 1d; for colony abbreviation see Table 1).

In 2007, a total of 752 males were collected from 60 colonies (Table 2). Five colonies, in which the queen or most of the workers had died, were excluded from further analyses. In all colonies, except RC8, queens had fully developed and activated ovaries with yellow bodies and maturing eggs.

Allozyme analyses revealed that males in mixed-species colonies were produced by the queen (e.g., CN13), by the workers (e.g., CN8) or both (e.g., RN5, NU12, CU15, Table 2). Queens of colonies UC6 and UC8 were homozygous for the $s$ allele, and $m$-males were therefore offspring of $T$. crassispinus workers, while the one $s$ male was son of a T. unifasciatus queen. All queens of colonies NU10 to NU15 were homozygous ff, and the $s$ and $m$-males were therefore offspring of $T$. unifasciatus workers.

In the CU colonies, $s$-males were presumably produced by $T$. unifasciatus workers, but $m$-males could in principle be sons of a $T$. crassispinus queen or T. unifasciatus workers. Mitochondrial DNA analysis revealed that the eight males in colony CU12 were offspring of T. unifasciatus workers, while the 18 males from the colony CU15 were produced by the $T$. crassispinus queen.

\section{Cuticular hydrocarbons of queens and workers from different species of Temnothorax ants}

The cuticular profiles of queens and workers of the six Temnothorax species consisted of a total of 64 peaks (Numbers of peaks in each species is given in Table 3). 40 peaks consistently appeared in all six species and 47 peaks could be identified by GC-MS [Additional file 1. Representative chromatography profiles from a queen of each species; Additional file 2. Proportions (\%) of peak 


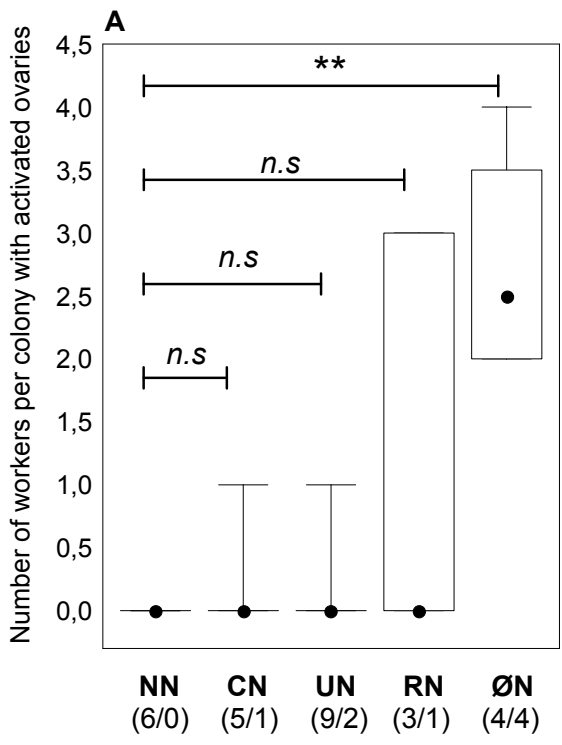

Colony group

(No. total colonies / No. colonies

with at least one worker with activated ovaries)

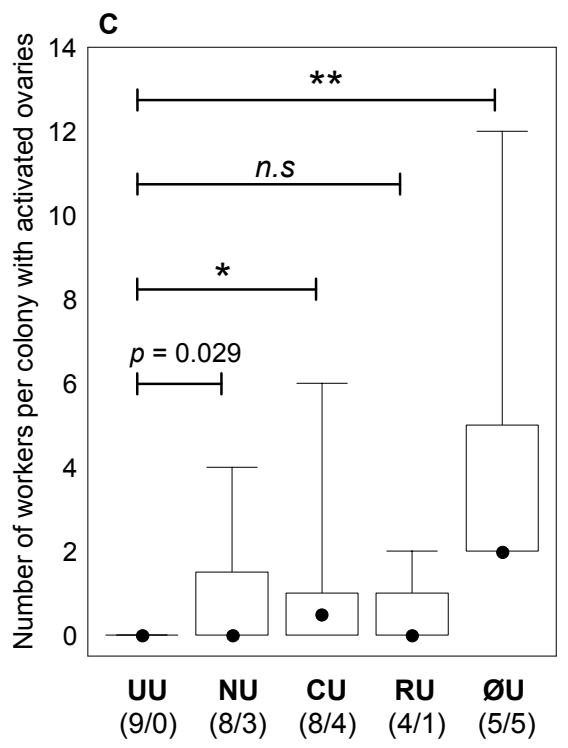

Colony group

(No. total colonies / No. colonies with at least one worker with activated ovaries)

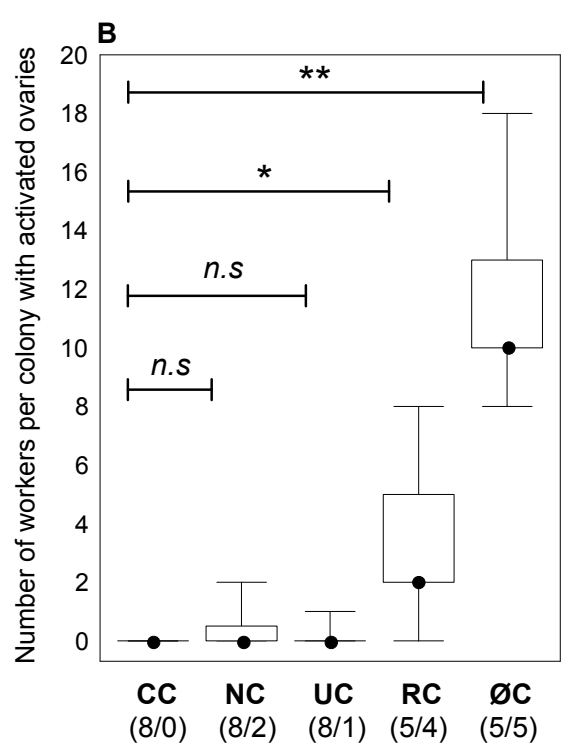

Colony group

(No. total colonies / No. colonies with at least one worker with activated ovaries)

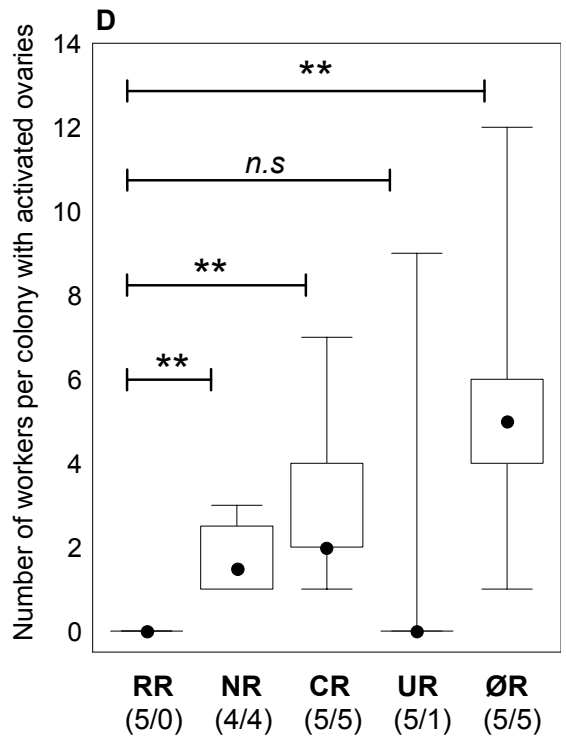

Colony group

(No. total colonies / No. colonies with at least one worker with activated ovaries)

Figure 1 a-d - Worker ovary activation in mixed species colonies of Temnothorax ants. Number of workers per colony with activated ovaries. Minimum and maximum (horizontal lines), first and third quartiles (rectangle), and the median (dot) are shown. The total number of colonies and the number of colonies with at least one worker with activated ovaries in each group is given in parentheses. $P$-values are from two-sample permutation tests $\left({ }^{*} p<0.01 ;{ }^{* *} p<0.0001\right.$; n.s. nonsignificant). After Bonferroni's correction, $p$-values of $<0.01$ are significant at the 0.05 level. 1a. T. nylanderi workers in colonies with a T. nylanderi queen (NN, control), T. crassispinus queen (CN), T. unifasciatus queen (UN), T. recedens queen (RN) and in colonies without a queen (ØN). 1b. T. crassispinus workers in colonies with a T. crassispinus queen (CC, control), $T$. nylanderi queen (NC), T. unifasciatus queen (UC), T. recedens queen (RC) and in colonies without a queen (ØC). 1c. T. unifasciatus workers in colonies with a T. unifasciatus queen (UU, control), T. nylanderi queen (NU), T. crassispinus queen (CU), T. recedens queen (RU) and in colonies without a queen $(\varnothing \mathrm{U}) .1 \mathrm{~d}$. T. recedens workers in colonies with a T. recedens queen (RR, control), T. nylanderi queen (NR), T. crassispinus queen $(\mathrm{CR})$, T. unifasciatus queen (UR) and in colonies without a queen (ØR). 
Table 1 Mixed-species colony set ups composed of four different Temnothorax species

\begin{tabular}{|c|c|c|c|c|c|c|c|}
\hline \multicolumn{2}{|c|}{ Colony composition } & \multirow{2}{*}{$\begin{array}{l}\text { Colony } \\
\text { name }\end{array}$} & \multirow{2}{*}{$\begin{array}{l}\text { Colonies } \\
\text { set up in } \\
2005\end{array}$} & \multirow{2}{*}{$\begin{array}{l}\text { Colonies set } \\
\text { up in } 2006\end{array}$} & \multirow{2}{*}{$\begin{array}{l}\text { No. } \\
\text { total } \\
\text { colonies }\end{array}$} & \multirow{2}{*}{$\begin{array}{l}\text { No. colonies used for the } \\
\text { assessment of ovary } \\
\text { activation }\end{array}$} & \multirow{2}{*}{$\begin{array}{l}\text { No. colonies used for the } \\
\text { assessment of worker male- } \\
\text { production }\end{array}$} \\
\hline Queen species & $\begin{array}{l}\text { Worker } \\
\text { species }\end{array}$ & & & & & & \\
\hline $\begin{array}{l}\text { T. nylanderi } \\
\text { (control) }\end{array}$ & T. nylanderi & NN & NN1 - NN5 & NN6 - NN15 & 15 & 10 & 5 \\
\hline T. crassispinus & & $\mathrm{CN}$ & CN1 - CN5 & CN6 - CN15 & 15 & 10 & 5 \\
\hline T. unifasciatus & & UN & UN1 - UN5 & UN6 - UN15 & 15 & 10 & 5 \\
\hline T. recedens & & RN & & RN1 - RN10 & 10 & 5 & 5 \\
\hline no queen & & $\varnothing \mathrm{N}$ & & $\varnothing N 1-\varnothing N 5$ & 5 & 5 & - \\
\hline $\begin{array}{l}\text { T. crassispinus } \\
\text { (control) }\end{array}$ & T. crassispinus & $\mathrm{CC}$ & CC1 - CC5 & CC6 - CC15 & 15 & 10 & 5 \\
\hline T. nylanderi & & NC & NC1-NC5 & NC6-NC15 & 15 & 10 & 5 \\
\hline T. unifasciatus & & UC & UC1 - UN5 & UC6 - UN15 & 15 & 10 & 5 \\
\hline T. recedens & & $\mathrm{RC}$ & & $\mathrm{RC} 1-\mathrm{RC} 10$ & 10 & 5 & 5 \\
\hline no queen & & $\varnothing c$ & & $\varnothing \subset 1-\varnothing<5$ & 5 & 5 & - \\
\hline $\begin{array}{l}\text { T. unifasciatus } \\
\text { (control) }\end{array}$ & T. unifasciatus & UU & UU1 - UU5 & UU6 - UU15 & 15 & 10 & 5 \\
\hline T. nylanderi & & NU & NU1-NU5 & NU6-NU15 & 15 & 10 & 5 \\
\hline T. crassispinus & & $\mathrm{CU}$ & CU1 - CU5 & CU6 - CU15 & 15 & 10 & 5 \\
\hline T. recedens & & $\mathrm{RU}$ & & RU1 - RU10 & 10 & 5 & 5 \\
\hline no queen & & $\varnothing \cup$ & & $\varnothing \cup 1$ - ØU5 & 5 & 5 & - \\
\hline $\begin{array}{l}\text { T. recedens } \\
\text { (control) }\end{array}$ & T. recedens & $\mathrm{RR}$ & & RR1 - RR10 & 10 & 5 & 5 \\
\hline T. nylanderi & & $N R$ & & NR1 - NR5 & 5 & 5 & - \\
\hline T. crassispinus & & $C R$ & & CR1 - CR5 & 5 & 5 & - \\
\hline T. unifasciatus & & UR & & UR1 - UR5 & 5 & 5 & - \\
\hline no queen & & $\varnothing R$ & & $\varnothing \mathrm{R} 1$ - ØR5 & 5 & 5 & - \\
\hline Total no. of color & & & 45 & 165 & 210 & 145 & 65 \\
\hline
\end{tabular}

areas from cuticular hydrocarbon extracts of queens and workers of each species; Additional file 3. Identification of cuticular compounds and differences of their relative amounts between queens $(\mathrm{Q})$ and workers $(\mathrm{W})$ of each species; see also [26] for identification of compounds in T. unifasciatus]. The profiles of queens and workers were predominantly characterized by the linear alkane $n-\mathrm{C}_{27}$ (Additional file 1, 2), while individuals of $T$. recedens were characterized by several longer chained hydrocarbons. Due to their very low abundance, peaks 36 to 40 and a few other peaks marked in Table S1 (Additional file 3) with an asterisk could not be identified. However, the latter peaks had exactly the same retention time as peaks in other species, which could be identified and are therefore assumed to be chemically identical to these compounds.

The chemical distances between T. nylanderi and T. crassispinus queens are lower compared to the other pair-wise comparisons among queens (Figure 2; Table 4). The groups of T. recedens queens and workers are chemically most distant from the groups of the other three Temnothorax species (Figure 2; Table 4). Interestingly, distances among queens are higher than among workers in four of six pair-wise comparisons (Table 4).

Within each species, chemical distances between groups of queens and workers are statistically significant and their cuticular profiles are classified correctly in a discriminant analysis (Table 3 ).

\section{Discussion and Conclusions}

Our study about the cross-specificity of the chemical compounds used in the regulation of reproduction in colonies of Temnothorax ants reveals a promising new approach to answering the question of whether queen pheromones are manipulative or honest signals. Queen pheromones appear to be less active across species-borders than within species. No worker reproduction was observed in single-species colonies. In contrast, queens were not able to fully prevent ovary development and male-production by workers from non-related species, 
Table 2 Male production by queens and workers in control and mixed-species colonies composed of different Temnothorax species

\begin{tabular}{|c|c|c|c|c|}
\hline Colony & $\begin{array}{l}\text { No. total males produced } \\
\text { per colony }\end{array}$ & $\begin{array}{l}\text { No. males Allozyme } \\
\text { electromorph }\end{array}$ & $\begin{array}{l}\text { No. males produced by the } \\
\text { queen }\end{array}$ & $\begin{array}{c}\text { No. males produced by } \\
\text { workers }\end{array}$ \\
\hline $\begin{array}{r}\text { NN11, NN13, NN14, } \\
\text { NN15 }\end{array}$ & none & & & \\
\hline CN7, CN12 & none & & & \\
\hline CN8 & 15 & $15 f$ & - & 15 \\
\hline CN13 & 3 & $3 m$ & 3 & - \\
\hline $\begin{array}{r}\text { UN7, UN11, UN12, UN14, } \\
\text { UN15 }\end{array}$ & none & & & \\
\hline RN4 & 3 & & 3 & - \\
\hline RN5 & 20 & & 11 & 9 \\
\hline RN6 & 20 & & 15 & 5 \\
\hline RN8 & 5 & & 5 & - \\
\hline CC12, CC13, CC14, CC15 & none & & & \\
\hline $\begin{array}{r}\text { NC11, NC12, NC13, } \\
\text { NC14, NC15 } \\
\end{array}$ & none & & & \\
\hline UC7, UC13, UC15 & none & & & \\
\hline UC6 & 3 & $1 s, 2 m$ & 1 & 2 \\
\hline UC8 & 1 & $1 \mathrm{~m}$ & - & 1 \\
\hline $\mathrm{RC} 3$ & 6 & & 6 & - \\
\hline RC4 & 2 & & 2 & - \\
\hline RC6 & 1 & & 1 & - \\
\hline RC8 & 54 & & 1 & $53^{*}$ \\
\hline UU6 & 1 & & 1 & - \\
\hline UU8 & 2 & & 2 & - \\
\hline UU9 & 1 & & 1 & - \\
\hline UU10 & 5 & & 5 & - \\
\hline UU12 & 29 & & 29 & - \\
\hline NU10 & 8 & $8 s$ & - & 8 \\
\hline NU12 & 74 & $42 s, 19 m, 13 f$ & 13 & 61 \\
\hline NU13 & 37 & $28 s, 3 m, 6 f$ & 6 & 31 \\
\hline NU14 & 13 & $6 s, 7 f$ & 7 & 6 \\
\hline NU15 & 59 & $59 \mathrm{~s}$ & - & 59 \\
\hline CU6 & 8 & $8 s$ & - & 8 \\
\hline CU9 & 2 & $2 s$ & - & 2 \\
\hline CU12 & 14 & $6 s, 8 m$ & - & 14 \\
\hline CU15 & 44 & $26 s, 18 m$ & 18 & 26 \\
\hline RU7 & 31 & & 31 & - \\
\hline RU8 & 95 & & 27 & 68 \\
\hline RU9 & 105 & & 105 & - \\
\hline RR1 & 27 & & 27 & - \\
\hline RR4 & 10 & & 10 & - \\
\hline RR5 & 7 & & 7 & - \\
\hline RR6 & 8 & & 8 & - \\
\hline RR8 & 24 & & 24 & - \\
\hline
\end{tabular}

*In colony RC8 the ovaries of the queen were not fully developed.

Numbers of males produced per colony by the queen or by workers are shown, respectively. Colony composition and colony names are explained in Table 1. Explanation of Allozyme electromorphs are given in the text. 
Table 3 Discriminant Analysis between groups of queens and workers within six Temnothorax species based on their specific cuticular hydrocarbon profiles

\begin{tabular}{llllll}
\hline Species & No. of peaks & Wilks' $\boldsymbol{\lambda}$ & F-values & $\boldsymbol{p}_{\text {-levels }}$ & correct classification \\
\hline T. nylanderi & 46 & 0.1098 & $\mathrm{~F}_{(7.7)}=8.105$ & $<0.01$ & $100 \%$ \\
T. crassispinus & 48 & 0.0068 & $\mathrm{~F}_{(10.4)}=58.828$ & $<0.001$ & $100 \%$ \\
T. unifasciatus & 46 & 0.0614 & $\mathrm{~F}_{(8.8)}=15.290$ & $<0.0001$ & $100 \%$ \\
T. recedens & 52 & 0.1919 & $\mathrm{~F}_{(11.32)}=12.248$ & $<0.0001$ & $100 \%$ \\
T. lichtensteini & 48 & 0.1326 & $\mathrm{~F}_{(8.14)}=11.453$ & $<0.0001$ & $100 \%$ \\
T. affinis & 46 & 0.1972 & $\mathrm{~F}_{(8.13)}=6.616$ & $<0.01$ & $100 \%$ \\
\hline
\end{tabular}

Percentages of correct classifications of individuals from predefined groups are given in the right column.

which indicates that queen pheromones are not fully conserved in evolution in this group of species. Furthermore, the rate of worker reproduction and ovary development of workers in mixed-species was lower than in queenless colonies, which speaks against the rapid evolution of queen pheromones expected from the queen control hypothesis.
These behavioral results are reflected in the chemical profiles of queens and workers, which in most pair-wise comparisons differed more between queens than between workers from different species but not tremendously so. This might suggest that queen bouquets diverge slightly more quickly than those of workers, but not at an extremely rapid speed. A faster divergence of

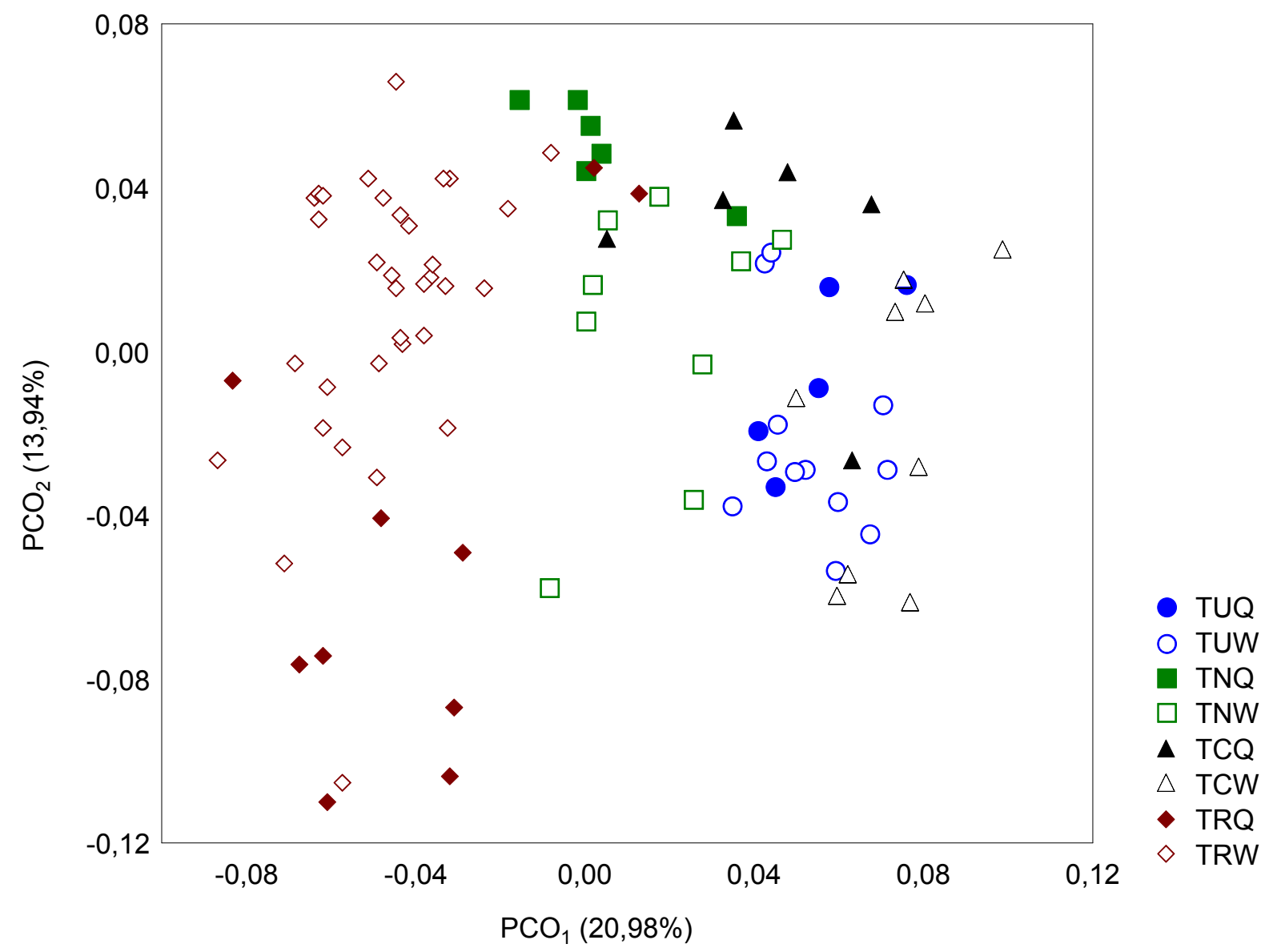

Figure 2 PCO ordination based on the cuticular hydrocarbons profiles from four Temnothorax species. Bidimensional PCO ordination based on the cuticular hydrocarbons profiles of queens $(\mathrm{Q})$ and workers $(\mathrm{W})$ from four different species of Temnothorax ants involved in the mixed-species experiment: T. unifasciatus (Tu $Q, n=5 ; T u W, n=12)$, T. nylanderi (Tn $Q, n=6 ; T n W ; n=9)$, T. crassispinus (Tc Q, $n=6 ; T c W, n=$ 9), $\operatorname{T}$. recedens $(\operatorname{Tr} Q, n=10 ; \operatorname{Tr} W ; n=34)$. The percentages of variance explained by the two main principal coordinates are given in parentheses. 
Table 4 Chemical distances between queens and workers among four Temnothorax species

\begin{tabular}{cccccccc}
\hline Queens & Tn Q & Tc Q & Tu Q & Workers & Tn W & Tc W & Tu W \\
\hline TcQ & $\mathbf{0 . 0 7 7}$ & & & TcW & 0.093 & & \\
TuQ & 0.108 & 0.088 & & TuW & 0.093 & $\mathbf{0 . 0 6 6}$ & \\
TrQ & 0.116 & 0.125 & 0.120 & TrW & 0.093 & 0.128 & 0.110 \\
\hline
\end{tabular}

Euclidean resemblance matrix based on cuticular hydrocarbon profiles of queens ( $Q$; left side) and workers (W; right side) from the four species of Temnothorax ants involved in the mixed-species experiment $(T n=T$. nylanderi, $T c=T$. crassispinus, $T u=T$. unifasciatus, $T r=T$. recedens). Figures in bold indicate a close Euclidean Distance between a pair of groups in contrast to the other compared pairs of groups.

queen- than worker-specific substances is in agreement with the hypothesis of a queen-worker arms race with manipulation and counter-manipulation. However, it might also reflect other forces of selection. For example, if queen-specific cuticular compounds were involved in attracting mates, avoidance of hybridization would quickly lead to species-specific queen bouquets. More information about the contexts in which cuticular substances are used in communication is therefore needed.

Studies on the paper wasp Polistes dominulus suggested a relatively high speed of evolution. Here, the cuticular hydrocarbons that differed between egg layers and non-reproductives varied even between different populations [27]. The observation that the chemical profiles of T. crassispinus and T. nylanderi queens are more similar compared to the other Temnothorax species, even though the two taxa diverged more than 1 Million years ago [28], makes similar intraspecific variation unlikely, but this remains to be investigated.

Our data do not reveal a clear trend in the chemistry of those hydrocarbons that differentiate queens and workers among the six investigated species. This matches the heterogeneous picture found in other, less closely related ants, where reproductives are characterized by particular long-chained hydrocarbons in some species but shorter or branched hydrocarbons in others [12,15,29-31]. However, it needs to be pointed out that it is usually not known, which of the large number of substances that differ between queens and workers are biologically active and which are mere side-products of the hydrocarbon metabolism without a function in communication [11].

Our study reveals a number of species idiosyncrasies that do not match phylogenetic relationships and are difficult to explain in the light of hypotheses about the nature of queen pheromones. For example, T. nylanderi and $T$. crassispinus workers seem to respond to the presence of a T. unifasciatus queen, while T. unifasciatus workers readily develop their ovaries in the presence of a T. nylanderi or T. crassispinus queen. This resembles the situation in honeybees, in which the presence of a heterospecific queen increases the rate of worker ovary activation strongly in Apis cerana but only slightly in Apis mellifera [32]. In contrast, workers of the bumblebee Bombus terrestris develop their ovaries in queenright colonies of the phylogenetically related B. lapidarius at a similar rate as under queenless conditions, but not in queenright homospecific colonies [33]. The results in these studies might have been affected by the presence of workers belonging to the species of the queen, as they might have an interest in preventing heterospecific workers from reproducing through aggression or egg eating. Worker nepotism might explain the common absence of reproduction by host workers in socially parasitic ants. Temnothorax workers are often parasitized by queens of slave-making species, such as Chalepoxenus, Myrmoxenus or Protomognathus. Though these genera are less closely related to Temnothorax than the pairs of species used in our study [e.g., [34]], enslaved workers rarely produce males [e.g., [35-37]]. Either slave-making queens have evolved particularly manipulative queen pheromones, which are active across large phylogenetic distances, or their reproductive monopoly is additionally enforced by aggression. Indeed, both queens and workers of slave-making ants have been observed to attack host workers in a way resembling the dominance interactions among the slave-makers themselves $[8,37]$.

Though our results do not allow drawing final conclusions about the speed of queen pheromone evolution, comparisons of their cross-species activity might help to learn more about the nature of such pheromones and how quickly they diverge among species. The heterogeneity of queen substances might reflect an ongoing arms race between queens and workers [14]. However, it might also be a consequence of species-specific queenbouquets serving to avoid hybridization. The fact that workers in mixed-species colonies did not behave like workers in queenless colonies strongly suggests that workers recognize queens belonging to another species and that queen pheromones regulating worker reproduction are partly conserved in evolution. This would be in agreement with the honest signal hypothesis.

\section{Methods}

In spring 2005 and 2006 we collected complete colonies of six different Temnothorax species: T. nylanderi (Förster, 1850) and T. affinis (Mayr, 1855) in Sommerhausen (Würzburg, Germany), T. crassispinus (Karavejev, 1926) in Unterisling (Regensburg, Germany), T. unifasciatus (Latreille, 1798) in Waldenhausen (Germany) and Gargnano (Lago di Garda, Italy) and T. recedens (Nylander, 1856) and T. lichtensteini (Bondroit, 1918) Gargnano (Lago di Garda, Italy). While $T$. nylanderi and T. crassispinus are closely related sibling species [38], the other four species are phylogenetically more distantly related (Additional file 4). 
Temnothorax colonies were collected from their nests in decaying branches on the ground and, in T. unifasciatus, $T$. lichtensteini and $T$. recedens, also from crevices in stone walls. The colonies were transferred into small plastic boxes $(10 \mathrm{~cm} \times 10 \mathrm{~cm} \times 3 \mathrm{~cm})$ with a regularly moistened plaster floor and kept in incubators under artificial climate conditions with the temperature gradually being raised from spring $\left(10^{\circ} \mathrm{C}\right.$ night $/ 20^{\circ} \mathrm{C}$ day) to summer $\left(17^{\circ} \mathrm{C}\right.$ night $/ 28^{\circ} \mathrm{C}$ day) conditions $[39,40]$. Twice per week, colonies were provided with water, honey, and pieces of cockroaches.

\section{Mixed-species colony set up}

In 2005, colonies of T. nylanderi, T. crassispinus and $T$. unifasciatus, with a sufficient amount of larvae in each colony, were chosen for the mixed-species experiment $(N=$ 45 colonies; Table 1). In 2006, the same mixed-species colonies were set up with additional mixed colonies plus $T$. recedens and colonies without a queen $(N=165$ colonies; Table 1). The number of worker pupae in $T$. recedens colonies was restricted; therefore, only five mixed colonies with $T$. recedens worker pupae were set up (Table 1 ). Mixed colonies were set up in early summer, when most larvae had developed into pupae. We transferred 50 worker pupae of the same species into a nest with either a queen from a different species in mixed colonies or a conspecific queen in control colonies (Table 1). To obtain the required sample size of 50 pupae, worker pupae were taken from five different con-specific colonies. No larvae or eggs were added to the colonies. To allow worker pupae to fully develop, we placed 30 marked adult workers from the colony of queen origin into each nest and removed them four weeks later after most of the pupae had developed into adult workers.

Several experimental colonies, in which the transferred worker pupae did not develop into adults (2005: 18 of 45 colonies; 2006, 8 of 100 colonies), had to be excluded from the study.

\section{Worker ovary activation}

In 2005, worker ovary activation was investigated in all colony set ups. In 2006, we investigated worker ovary activation in all colonies without a queen, all colonies with $T$. recedens workers and a queen from a different species, and five randomly chosen colonies of each of the remaining colony set ups (total $N=145$ colonies; Table 1). The colonies were frozen six weeks after the transferred worker pupae had developed into adult worker, and workers and queens were dissected to assess their ovary activation [41]. Workers having elongated ovaries (> $1 \mathrm{~mm}$ ) with viable, oval eggs similar in shape and color to those found in the ovaries of queens were classified as "fertile".
For statistical analyses, two sample permutation tests were used to assess the difference of numbers of fertile workers per colony between groups of control colonies and mixed colonies and between control colonies and colonies without a queen.

\section{Male-production by workers}

The remaining 65 colonies of the 2006 set up were kept in incubators (gradual decrease of temperature to $0^{\circ} \mathrm{C}$ night $/ 10^{\circ} \mathrm{C}$ day for 15 weeks and gradual increase again to $17^{\circ} \mathrm{C}$ night $/ 28^{\circ} \mathrm{C}$ day thereafter) until hibernated brood had developed in 2007 (Tables 1 and 2). From May to August 2007 all freshly enclosed adult males were collected and frozen at $-20^{\circ} \mathrm{C}$ for further analyses. After all male pupae had enclosed, all colonies were frozen and queens were dissected to determine their ovarian status.

T. nylanderi, T. crassispinus and T. unifasciatus males are of dark brown pigmentation. $T$. recedens males have a pale pigmentation and could easily be distinguished from males of the other three species by inspecting their coloration. T. nylanderi, T. crassispinus and T. unifasciatus males are morphologically similar and thus were distinguished by electrophoresis of the glucose-6-phosoate isomerase [GPI; $[27,38]]$ or sequencing the mitochondrial cytochrome b (Cyt b) gene.

\section{Allozyme analyses}

Electrophoresis of glucose-6-phosoate isomerase for Temnothorax ants has been described previously [27]. Electromorphs were named according to their migration velocities in the gel (fast $f$; medium $m$; slow $s$ ). T. crassispinus and T. nylanderi are fixed almost completely for the electromorphs $m$ and $f$, respectively [27,38] and T. nylanderi occasionally exhibits the electromorph $s$ [27]. In T. unifasciatus, 32 of 36 workers from 20 colonies were homozygous for the electromorph $s$ and 4 were heterozygous with electromorph genotype $s m$ [see also [42]]. Queens were analyzed when necessary.

The gasters of individual workers and queens were homogenized in $20 \mu \mathrm{l}$ Tris-EDTA pH 7.0 buffer. Proteins were separated by $90 \mathrm{~min}$ electrophoresis at $10 \mathrm{~V} /$ $\mathrm{cm}$ and $20 \mathrm{~mA}$ on $10 \mathrm{~cm} \times 8 \mathrm{~cm} \times 0.75 \mathrm{~mm} 7.5 \%$ polyacrylamide slab gels using a Tris-glycine $\mathrm{pH} 8.3$ buffer. The enzyme was stained using standard histochemical techniques [43].

\section{Mitochondrial analyses}

When males could not be distinguished by electrophoresis, we in addition sequenced the cytochrome b (Cyt b) gene. DNA was extracted from the gasters of males using the CTAB method (1\%) as previously described [44]. The mitochondrial cytochrome b (Cyt b) gene was analyzed using the primers CbI (CB-J-10933) and 16Sar (LR-N-13398) [45]. The $20 \mu \mathrm{l}$ PCR reaction mixture 
consisted of $1 \mu \mathrm{l}$ DNA, $0.125 \mathrm{mM}$ dNTPs, $0.25 \mu \mathrm{M}$ of each primer, $11.1 \mu \mathrm{l}$ dd $\mathrm{H}_{2} \mathrm{O}, 2 \mu \mathrm{l} 10 \times$ PCR buffer (MBI), $2.5 \mathrm{mM} \mathrm{MgCl}$ and $1 \mu \mathrm{l}$ of 1 unit/ $\mu \mathrm{l}$ Taq Polymerase. Genes were amplified at an annealing temperature of $48^{\circ} \mathrm{C}$ with 38 cycles. PCR products were separated by electrophoresis on a $1 \%$ ethidiumbromidestained agarose gel (TAE buffer) for $30 \mathrm{~min}$ at $100 \mathrm{~mA}$ and then purified with High Pure PCR cleanup Micro Kit (Roche). Cycle sequencing was carried out with $3 \mu \mathrm{l}$ of purified PCR-Product using ABI-Cycle sequencing Kit Version 1.1. Single-stranded PCR products were sequenced using an ABI PRISM 310 automatic sequencer (Perkin-Elmer, Applied Biosystems). The first 450 base pairs of the Sequences representing the Cyt b gene were read and aligned with Sequencing Analysis Software version 3.4 (Perkin-Elmer, Applied Biosystems).

\section{Cuticular hydrocarbons of queens and workers from different species of Temnothorax ants}

To estimate the chemical distances between the four species of Temnothorax ants used for the mixed-species colony set ups, queens and workers from T. nylanderi, $T$. crassispinus, T. unifasciatus, and T. recedens were analyzed. For the identification of queen specific signals, queens and workers from two additional species, T. affinis and T. lichtensteini, were included in the analysis. From each species the queens of 5 to 10 unmanipulated colonies plus 1 to 3 workers from each of the colonies were chemically analyzed. All colonies were collected in spring 2006 (see above). T. unifasciatus colonies were used only from the population in Italy.

\section{Chemical Analysis}

Hydrocarbons were extracted four to five weeks after colonies had been subjected to artificial summer condition $\left(17^{\circ} \mathrm{C}\right.$ night $/ 28^{\circ} \mathrm{C}$ day; see above). Workers were frozen and hydrocarbons were obtained through solvent extraction by individually immersing each worker for $10 \mathrm{~min}$ in $20 \mu \mathrm{l}$ pentane. After evaporation of the solvent, the residues were re-dissolved in $15 \mu$ l pentane, of which $2 \mu \mathrm{l}$ were injected into an Agilent Technologies $6890 \mathrm{~N}$ gas chromatograph. Hydrocarbons of queens were obtained through SPME (Solid Phase Micro Extraction) which gives qualitative and quantitative similar results [46]. A $30 \mu \mathrm{m}$ polydimethylsiloxane fiber was gently rubbed for $10 \mathrm{~min}$ against the gaster of the immobilized queen and injected into the injection port of the same gas chromatograph as above. The gas chromatograph was equipped with a flame ionization detector and a HP-5 capillary column $(30 \mathrm{~m} \times 0.32 \mathrm{~mm} \times$ $0.25 \mu \mathrm{m}$, J\&W Scientific, USA). The injector was split/ splitless and the carrying gas was helium at $1 \mathrm{ml} / \mathrm{min}$. The same temperature program was used for the solvent and the solid phase micro extraction with the temperature initially held at $70^{\circ} \mathrm{C}$ for $1 \mathrm{~min}$, increased from $70^{\circ} \mathrm{C}$ to $180^{\circ} \mathrm{C}$ at $30^{\circ} \mathrm{C} / \mathrm{min}$, from $180^{\circ} \mathrm{C}$ to $310^{\circ} \mathrm{C}$ at $5^{\circ} \mathrm{C} /$ min, and held constant at $310^{\circ} \mathrm{C}$ for $5 \mathrm{~min}$.

For identification of the peaks, the pooled extracts of 30 workers of each species were injected into a combined gas chromatography and mass spectrometry (GCMS; Agilent Technologies $6890 \mathrm{~N}$ ) equipped with a RH$5 \mathrm{~ms}+$ fused silica capillary column $(30 \mathrm{~m} \times 0.25 \mathrm{~mm} \times$ $0.25 \mu \mathrm{m}$, J\&W Scientific, USA). The injector was split/ splitless $\left(250^{\circ} \mathrm{C}\right)$ with the purge valve opened after 60 sec and the carrying gas was helium at $1 \mathrm{ml} / \mathrm{min}$. Temperature was held constant for $1 \mathrm{~min}$ at $60^{\circ} \mathrm{C}$, increased from $60^{\circ} \mathrm{C}$ to $300^{\circ} \mathrm{C}$ at $5^{\circ} \mathrm{C} / \mathrm{min}$ and held constant for 10 min at $300^{\circ} \mathrm{C}$. The electron impact mass spectra (EI-MS; Agilent 5973 inert mass selective detector) were recorded with an ionization voltage of $70 \mathrm{eV}$, a source temperature of $230^{\circ} \mathrm{C}$ and an interface temperature of $315^{\circ} \mathrm{C}$. We identified $n$-alkanes by comparing mass spectra with data from a commercial MS library (NIST, Gaithersburg, MD, USA). Methyl-alkanes were identified by diagnostic ions, standard MS databases (see above), and by determining Kovats indices by the method of Carlson et al. [47]. MSD ChemStation Software (Agilent Technologies, Palo Alto, CA, USA) for Windows was used for data acquisition.

For statistical analysis of the chemical distance between the four species involved in the mixed-species experiment, we included peaks consistently present in queens and workers of all four species, plus peaks with a relative area of more than $1 \%$ that were present in at least $50 \%$ of individuals in a group of workers or queens within each species. Standardized peak areas were transformed by square root. Principle coordinate (PCO) analyses based on Gower's centered matrix was used to visualize the patterns of differences in the multivariate chemical structure among groups [48-50]. Euclidean distance matrix was analyzed based on centroids of groups calculated from principle coordinates. PCO and Euclidean distance analyses were performed using the program PCO [49].

For the identification of queen specific signals we analyzed each species separately and included peaks consistently present in the groups of queens and workers within each species. Standardized peak areas were transformed by using the formula: $\mathrm{Zij}=\log [\mathrm{X} i, j / \mathrm{g}(\mathrm{X} j)]$, with $\mathrm{X} i, j$ being the standardized peak area $i$ for the sample $j$, and $\mathrm{g}(\mathrm{X} j)$ the geometric mean of all peaks of the sample $j$ [51]. For multivariate analyses, the number of variables was reduced by principle component analysis (PCA). The factor scores obtained by PCA were used in a subsequent discriminant analyses (DA) to determine whether groups could be distinguished on the basis of their cuticular profiles. Wilks' $\lambda$ significance and the percentage of correct assignments were used to evaluate the validity of the discriminant function. We used 
Mann-Whitney U-tests to compare percentages of single compounds between groups and adjusted $p$-values for multiple comparisons using Bonferroni's method. PCA and DA analyses were performed using Statistica 6.0.

\section{Additional material}

Additional file 1: Gas chromatography profiles. Representative gas chromatography profiles of queens from six Temnothorax species. Peaks used for the statistical analysis are marked with numbers. Identification of peaks is given in Additional file 3.

Additional file 2: Proportion of peak areas. Proportions (\%) of peak areas in chromatograms from cuticular hydrocarbon extracts of queens and workers in six Temnothorax species. Box plots show medians and $25 \%$ and $75 \%$ quartiles. Whiskers depict the range of $90 \%$ of all cases. Extreme outliers are denoted by circles. P-values of substances differing significantly between the various groups are given in Additional file 3 .

Additional file 3: Table S1 - Identification of cuticular compounds. Identification of cuticular compounds and differences of their relative amounts between queens $(\mathrm{Q})$ and workers $(\mathrm{W})$ in five Temnothorax species. The number of samples of queens and workers is given in parentheses. Peak numbers correspond with numbers in Additional file 1 and 2. Directions of difference are shown in Additional file 2. Bold pvalues from Mann-Whitney U-tests are significant at the $5 \%$ probability after Bonferroni's correction $\left(p^{\prime}<0.001\right)$; $n . s=$ not significant. *Due to very low abundance, peaks marked with a star could not be identified. They had exactly the same retention time in GC as peaks in other species, which could be identified. We therefore assume these compounds to be chemically identical.

\section{Additional file 4: Phylogenetic tree of Temnothorax species}

Phylogenetic tree of Temnothorax species. Majority rule consensus tree recovered in a Bayesian analysis (4,000,000 generations) with the GTR + I $+\mathrm{G}$ model. The tree is based on 651 base pairs of the mitochondrial CO I gene and numbers represent clade credibility values (J. Beibl, pers. comm.).

\section{Acknowledgements}

This work was supported by Deutsche Forschungsgemeinschaft (He 1623/ 17). Tina Wanke and Sabine Frohschammer kindly helped in the field. We hereby declare that the experiments comply with the current laws of Germany.

\section{Author details}

'LS Biologie I, Universität Regensburg, 93040 Regensburg, Germany. ${ }^{2}$ Max Planck Institute for Chemical Ecology, 07745 Jena, Germany.

\section{Authors' contributions}

EB participated in the design of the study, performed all behavioural, morphological, allozyme, chemical, and statistical analyses and participated in writing the manuscript. JK identified the compounds in the chemical analysis. AT carried out the mitochondrial analysis. $\mathrm{JH}$ conceived of the study, participated in its design and in writing the manuscript. All authors read and approved the final manuscript.

Received: 15 June 2010 Accepted: 1 March 2011

Published: 1 March 2011

\section{References}

1. Hölldobler B, Wilson EO: The Superorganism: The Beauty, Elegance, and Strangeness of Insect Societies London: W.W. Norton \& Company; 2008.

2. Wilson EO: The insect societies Cambridge, Mass: Harvard University Press; 1971.

3. Hammond RL, Keller L: Conflict over male parentage in social insects. PLoS Biology 2004, 2:e248.

4. Heinze J: Reproductive conflict in insect societies. Adv Stud Behav 2004, 34:1-57.
5. Bourke AFG: Worker reproduction in the higher eusocial Hymenoptera. $Q$ Rev Biol 1988, 63:291-311.

6. Choe JC: Worker reproduction and social evolution in ants (Hymenoptera: Formicidae). In Advances in Myrmecology. Edited by: Trager JC. Leiden: Brill E. J; 1988:163-187.

7. Brunner $\mathrm{E}$, Heinze $\mathrm{J}$ : Worker dominance and policing in the ant Temnothorax unifasciatus. Insectes Soc 2009, 56:397-404.

8. Franks NR, Scovell E: Dominance and reproductive success among slavemaking worker ants. Nature 1983, 304:724-725.

9. Kikuta N, Tsuji K: Queen and worker policing in the monogynous and monandrous ant, Diacamma sp. Behav Ecol Sociobiol 1999, 46:180-189.

10. Wenseleers T, Tofilski A, Ratnieks FLW: Queen and worker policing in the tree wasp Dolichovespula sylvestris. Behav Ecol Sociobiol 2005, 58:80-86.

11. Heinze J, d'Ettorre P: Honest and dishonest communication in social Hymenoptera. J Exp Biol 2009, 212:1775-1779.

12. Monnin T: Chemical recognition of reproductive status in social insects. Ann Zool Fennici 2006, 43:515-530.

13. Hefetz A, Katzav-Gozansky T: Are multiple honeybee queen pheromones indicators for a queen-workers arms race? Apiacta 2004, 39:44-52.

14. Katzav-Gozansky T: The evolution of honeybee multiple queenpheromones - a consequence of a queen-worker arms race? Braz $J$ morph Sci 2006, 23:129-136.

15. Holman L, Jørgensen CG, Nielsen J, d'Ettorre P: Identification of ant queen pheromone regulating worker sterility. Proc $R$ Soc B 2010, 277:3793-3800.

16. Hölldobler B, Wilson EO: Queen control in colonies of weaver ants (Hymenoptera: Formicidae). Ann Entomol Soc Am 1983, 76:235-238.

17. Kaatz $\mathrm{HH}$, Hildebrand $\mathrm{H}$, Engels W: Primer effect of queen pheromone on juvenile hormone biosynthesis in adult worker honey bees. J Comp Physiol B 1992, 162:588-592.

18. Keller $L$, Nonacs $P$ : The role of queen pheromones in social insects: queen control or queen signal? Anim Behav 1993, 45:787-794.

19. Ratnieks FLW: Reproductive harmony via mutual policing by workers in eusocial Hymenoptera. Am Nat 1988, 132:217-236.

20. Wenseleers T, Hart AG, Ratnieks FLW: When resistance is useless: Policing and the evolution of reproductive acquiescence in insect societies. Am Nat 2004, 164:E154-E167.

21. Wenseleers $T$, Helanterä $H$, Hart $A$, Ratnieks FLW: Worker reproduction and policing in insect societies: an ESS analysis. J Evol Biol 2004, 17:1035-1047.

22. d' Ettorre P, Heinze J, Schulz C, Francke W, Ayasse M: Does she smell like a queen? Chemoreception of a cuticular hydrocarbon signal in the ant Pachycondyla inversa. J Exp Biol 2004, 207:1085-1091.

23. Ratnieks FLW, Wenseleers T: Altruism in insect societies and beyond: voluntary or enforced? Trends Ecol Evol 2008, 23:45-52.

24. Wenseleers T, Ratnieks FLW: Comparative analysis of worker reproduction and policing in eusocial Hymenoptera supports relatedness theory. Am Nat 2006, 168:E163-E179.

25. Wenseleers T, Ratnieks FLW: Enforced altruism in insect societies. Nature 2006, 444:50.

26. Brunner $\mathrm{E}$, Kroiss J, Heinze J: Chemical correlates of reproduction and worker policing in a myrmicine ant. J Insect Physiol 2009, 55:19-26.

27. Dapporto L, Theodora P, Spacchini C, Pieraccini G, Turillazzi S: Rank and epicuticular hydrocarbons in different populations of the paper wasp Polistes dominulus (Christ) (Hymenoptera, Vespidae). Insectes Soc 2004, 51:279-286.

28. Pusch K, Seifert B, Foitzik S, Heinze J: Distribution and genetic divergence of two parapatric sibling ant species in Central Europe. Biol J Linn Soc 2006, 88.

29. Endler A, Liebig J, Schmitt T, Parker JE, Jones GR, Schreier P, Hölldobler B: Surface hydrocarbons of queen eggs regulate worker reproduction in a social insect. Proc Natl Acad Sci USA 2004, 101:2945-2950.

30. de Biseau JC, Passera L, Daloze D, Aron S: Ovarian activity correlates with extreme changes in cuticular hydrocarbon profile in the highly polygynous ant, Linepithema humile. J Insect Physiol 2004, 50:585-593.

31. van Zweden JS, Heinze J, Boomsma JJ, d'Ettorre P: Ant queen egg-marking signals: matching deceptive laboratory simplicity with natural complexity. PLoS One 2009, 4:e4718.

32. Tan $K$, Yang M, Radloff $S$, Pirk CWW, Crewe R, Phiancharoen M, Hepburn HR, Oldroyd BP: Worker reproduction in mixed-species colonies of honey bees. Behav Ecol 2009, 20:1106-1110.

33. Alaux C, Hefetz A, Jaisson P: Plasticity of worker reproductive strategies in Bombus terrestris: lessons from artificial mixed-species colonies. Anim Behav 2006, 72:1417-1425. 
34. Beibl J, Stuart RJ, Heinze J, Foitzik S: Six origins of slavery in formicoxenine ants. Insectes Soc 2005, 52:291-297.

35. Foitzik S, Herbers JM: Colony structure of a slavemaking ant. I. Intracolony relatedness, worker reproduction, and polydomy. Evolution 2001, 55:307-315.

36. Heinze J: Reproductive hierarchies among workers of the slave-making ant, Chalepoxenus muellerianus. Ethology 1996, 102:117-127.

37. Heinze J: The reproductive potential of workers in slave-making ants. Insectes Soc 1996, 43:319-328

38. Seifert B: Two new Central European subspecies of Leptothorax nylanderi (Förster, 1850) and Leptothorax sordidulus (Müller, 1923) (Hymenoptera: Formicidae). Abhandlungen und Berichte des Naturkundemuseums Görlitz 1995, 68:1-18.

39. Buschinger A: Experimente und Beobachtung zur Gründung und Entwicklung neuer Sozietäten der sklavenhaltenden Ameise Harpagoxenus sublaevis (Nyl.). Insectes Soc 1974, 21:381-406.

40. Heinze J, Ortius D: Social organization of Leptothorax acervorum from Alaska (Hymenoptera: Formicidae). Psyche 1991, 98:227-240.

41. Buschinger A, Alloway TM: Caste polymorphism in Harpagoxenus canadensis M. R. Smith (Hym., Formicidae). Insectes Soc 1978, 25:339-350.

42. Heinze J, Puchinger W, Hölldobler B: Worker reproduction and social hierarchies in Leptothorax ants. Anim Behav 1997, 54:849-864.

43. Murphy RW, Sites JW jr, Buth GD, Haufler CH: Proteins: Isozyme electrophoresis. In Molecular Systematics. Edited by: Hills DM, Moritz C, Mable BK. Sunderland, Massachusetts: Sinauer Associates; 1996:51.

44. Sambrook J, Russell DW: Molecular Cloning: A Laboratory Manual. 3 edition. Cold Spring Harbor, New York: Cold Spring Harbor Laboratory Press; 2001.

45. Simon C, Frat F, Beckenbach A, Crespi BJ, Liu H, Flook P: Evolution, weighting, and phylogenetic utility of mitochondrial gene sequences and a compilation of conserved polymerase chain reaction primers. Ann Entomol Soc Am 1994, 87:651-701.

46. Tentschert J, Bestmann HJ, Heinze J: Cuticular compounds of workers and queens in two Leptothorax ant species - a comparison of results obtained by solvent extraction, solid sampling, and SPME. Chemoecology 2002, 12:15-21.

47. Carlson DA, Bernier UR, Sutton BD: Elution patterns from capillary GC for methyl-branched alkanes. J Chem Ecol 1998, 24:1845-1865.

48. Gower JC: Some distance properties of latent root and vector methods used in multivariate analysis. Biometrika 1966, 53:325-338.

49. Anderson MJ: PCO: a FORTRAN computer program for principal coordinate analysis. Department of Statistics, University of Auckland, New Zealand; 2003.

50. Mardon J, Saunders SM, Anderson MJ, Couchoux C, Bonadonna F: Species, Gender, and Identity: Cracking Petrel's Sociochemical Code. Chemical Senses 2010, 35:309-321.

51. Reyment RA: Compositional data analysis. Terra Rev 1989, 1:29-34.

doi:10.1186/1471-2148-11-55

Cite this article as: Brunner et al:: Queen pheromones in Temnothorax ants: control or honest signal? BMC Evolutionary Biology 2011 11:55.

\section{Submit your next manuscript to BioMed Central and take full advantage of:}

- Convenient online submission

- Thorough peer review

- No space constraints or color figure charges

- Immediate publication on acceptance

- Inclusion in PubMed, CAS, Scopus and Google Scholar

- Research which is freely available for redistribution

Submit your manuscript at www.biomedcentral.com/submit
Ciomed Central 